Sarnklong C, Cone JW, Pellikaan W and Hendriks WH 2009. Utilization of rice straw and different treatments to improve its feed value for ruminants: a review. AsianAustralasian Association of Animal Production Societies. Retrieved from http://www.thefreelibrary.com/Utilization + of + rice + straw + and + different + treatments + to+improve+its...-a022531487. May 10, 2010.

Zhenhai Y and Tingshuang G 1999. New developments in livestock systems based on crop residues. Retrieved from http://www.cd3wd.com/cd3wd_40/lstock/003/ FeedEconf2/conf96pdf/guo.pdf. May 10, 2010.

\title{
Study on the ensiling effect of Galega Orientalis Lam. Cv. Xinyin No.1 treated with different methods
}

\author{
Dong Zhiguo ${ }^{\dagger}$ \\ Grassland Institute, Xinjiang Academy of Animal Science, Karamay Ave.East No.151, 830000 Urumqi, Xinjiang, China
}

Introduction

Galega orientalis Lam. cv. Xinyin No. 1 is legume forage which was bred and introduced by the Grassland Institute of Xinjiang Academy of Animal Science. The utilization ratio of its hay is low in the dairy industry farmers prefer silage which avoids losses associated with hay production. However it is difficult to succeed in ensiling this species by routine methods because of the low solubility level of this leguminous forage. This experiment was done to investigate ensiling results using Galega orientalis Lam.cv. Xinyin No. 1 with added PFJ.

\section{Material and methods}

Test material was the 1st cut of 3-year-growth grass of Galega orientalis Lam. cv. Xinyin No. 1, mown in the original florescence. PFJ (Previously fermented juices fermenting) needs to be made in advance before ensiling. Take just the right amount of fresh Galega orientalis Lam. cv. Xinyin No. 1 cut it short, crush after adding a little distilled water, get green juice after filtering, then add $0.5 \%$ of deoxidation candy, ferment in a hermetic and anaerobium jar under a certain temperature for 2 days, get previously fermented juices and add into the raw material at a $1 \%$ rate. The ensiling method was to store silage in a bottle. There were four treatments: new fresh grass ensiled directly, withered grass ensiling, fresh grass adding PFJ and withered grass adding PFJ. Every treatment had three repetitions. The grass of every treatment is cut to $1 \mathrm{~cm}$ long, then put into the one litre bottles and pressed tightly. Some raw material grass was dried to check nutrition while making silage. Fresh grass ensiling is: put the grass into the bottles directly after cutting. When adding PFJ to Fresh grass sprinkle $1 \%$ PFJ on fresh grass and blend. Withering silage : ensile the grass dried after achieving a flaccid state through exposure to the sun (moisture content about $55 \%$ ), For Withered grass add PFJ by sprinkling $1 \%$ PFJ to the withered grass (moisture content about $55 \%$ ) and blend equably. After filling was finished, the bottlenecks were completely sealled using the bottle cap and adhesive tape Each bottler was dated. After completing silage, the bottles were placed to store in shade for 50 days then opened for testing.

\section{Results}

The difference of CP and NDF contents of silage disposed by half-hay $+P F J$ is not significant $(P>0.05), C P$ and NDF as contents are merely $4.3 \%$ and $0.5 \%$ less than raw material respectively, and its $\mathrm{NH} 3-\mathrm{N}\left(18 \mathrm{ug} \cdot 100 \mathrm{ml}^{-1}\right)$ and $\mathrm{pH}(4.4)$ of silage is lowest in all the treatments. As a result, the fermenting effect of the team half hay + PFJ is best. These results explain that adding PFJ can promote lactic acid needed to ferment so enhancing the fermenting quality of silage and maintaining the nutrient value of Galega orientalis Lam. cv. Xinyin No. 1 better.

Table 1 Comparison on Chemical Composition of Raw Material Grass and Silage \%

\begin{tabular}{lcccc}
\hline \hline & Fresh Grass & Fresh Grass + PFJ & Withering Ensiling & Withered Grass + PFJ \\
\hline $\mathrm{NH}_{3}-\mathrm{N}$ & $30^{\mathrm{a}}$ & $28^{\mathrm{a}}$ & $20^{\mathrm{b}}$ & $18^{\mathrm{b}}$ \\
$\mathrm{pH}$ & $5.7^{\mathrm{a}}$ & $5.5^{\mathrm{a}}$ & $4.8^{\mathrm{b}}$ & $4.4^{\mathrm{b}}$ \\
\hline \hline
\end{tabular}

\footnotetext{
${ }^{\dagger}$ E-mail: dzg_0@sina.com
} 
Table 2 Comparison on $\mathrm{NH}_{3}-\mathrm{N}$ and $\mathrm{pH}$ of Silageug $\cdot 100 \mathrm{ml}^{-1}$

\begin{tabular}{lccccc}
\hline \hline & Raw Grass & Fresh Grass & Fresh Grass + PFJ & Withering Ensiling & Withered Grass + PFJ \\
\hline Moisture & 75.84 & 75.24 & 75.81 & 55.33 & 55.93 \\
CP & $23.88^{\mathrm{a}}$ & $21.84^{\mathrm{b}}$ & $21.97^{\mathrm{b}}$ & $22.68^{\mathrm{a}}$ & $23.45^{\mathrm{a}}$ \\
NDF & $49.20^{\mathrm{a}}$ & $46.10^{\mathrm{b}}$ & $46.70^{\mathrm{b}}$ & $47.62^{\mathrm{a}}$ & $48.70^{\mathrm{a}}$ \\
ADF & $38.00^{\mathrm{c}}$ & $36.30^{\mathrm{b}}$ & $36.50^{\mathrm{b}}$ & $35.74^{\mathrm{b}}$ & $33.10^{\mathrm{a}}$ \\
\hline \hline
\end{tabular}

\section{Conclusions}

Adding additive is an effective measurement to ensure ferment quality of silage of Galega orientalis Lam. cv. Xinyin No. 1 stable. The treatment of withered grass with PFJ maintains a good quality of nutrition, which is an ideal outcome to making silage. Furthermore, PFJ from forage is a better and natural biological additive.

\section{Acknowledgements}

The authors gratefully acknowledge founding from the Sci-tech department of Xinjiang Autonomous. 